\title{
Dialogue interaction as a design tool for academic research. A case study of UFRJ's extension project on future of food with the youth from periphery
}

\author{
Rita Afonso ${ }^{1 . a}$, Roberto Bartholo ${ }^{2}$, Cristine Carvalho ${ }^{3}$, Dorothea Klein ${ }^{4}$, Ivan Bursztyn ${ }^{5}$ \\ ${ }^{1}$ Federal University of Rio de Janeiro - Faculty of Business Administration - ritaafonso@facc.ufrj.br \\ ${ }^{2}$ Federal University of Rio de Janeiro - Graduate Program in Production Engineering - bartholo.roberto@gmail.com \\ ${ }^{3}$ Federal University of Rio de Janeiro - Graduate Program in Production Engineering - cristine.c.carvalho@gmail.com \\ ${ }^{3}$ The University of Sheffield - Geography Department - d.j.kleine@sheffield.ac.uk \\ ${ }^{3}$ Federal University of Rio de Janeiro - Institute of Nutrition Josué de Castro - ivan@gastronomia.ufrj.br
}

\begin{abstract}
The paper presents the research project "Food 2.0: Sustainable Food Futures - young people's views from Rio and London", designed to disclose the views of young people living in the peripheries of Rio de Janeiro and London on their food futures. The project was conceived and implemented in dialogical and participatory way using new technologies of information and communication. It was part of university extension activities from the Federal University of Rio de Janeiro (UFRJ).
\end{abstract}

Keywords. University Extension; Design for social action; Food; Participatory research

\section{Introduction}

Brazil is the 9th largest economy (IMF, 2016), and still one of the most unequal societies in the world, with a Gini index of 0.49 (2014). Government policies, including school meals policy, focus on reducing this inequality and have shown some effect. However, the expectations of young people from disadvantaged urban areas, such as favelas, about the future of food are still poorly heard.

The importance of higher education in the desired changes in current food systems has been highlighted internationally. Greater emphasis is placed on contributions involving adaptations and practices of small farmers' production, food security and sovereignty, preservation of local culture and ecosystems, the rescue of the pleasure of tasting and the implications of the continuous use of pesticides (BARLETT, 2011).

Inspired by these issues that run through food security and the health of the population, UFRJ's Laboratory of Technology and Social Development LTDS - conduced the extension project named "Food 2.0: Sustainable Food Futures - young people's views from Rio and London"1, a research project aims at bring

\footnotetext{
${ }^{1}$ The project was included in Call for Proposals 38/2014, funded by the UK Research Council (RCUK) and the National Council of State Funds for Research Support (CONFAP), in Brazil funded by FAPERJ - Fundação Carlos Chagas Filho de
}

to the surface the youthful perspective on food future from the Rio de Janeiro and London peripheries in dialogue with participants and students from the University, changing knowledge about food production, consumption and food culture, managing audio-visual tools and media to design the results for the academic research question: What is the future of food? And how the audio-visual tool can be used as a methodology to express the results? As an interdisciplinary project, it explored with youth in low income urban settings how they conceptualise sustainable food.

It was possible to verify in the videos produced by the youths, the reflection on the subject of food sovereignty and the future of food. In terms of content, the groups produced a rather critical discourse: against explorations of the "economic, industrial and media (big media) system", with emphasis on cases that counter the criticized model: traditional, local, community initiatives.

\section{Food sustainability and university: a necessary dialogue to be designed}

\subsection{Sustainability and culture on food issues}

Recently a new discourse and a new concern within international hegemonic environmentalist thinking point

Amparo à Pesquisa do Estado do Rio de Janeiro. This paper refers to the project activities in Brazil.

\footnotetext{
${ }^{\mathrm{a}}$ Corresponding author: ritaafonso@facc.ufrj.br
} 
to a redefinition of the main cause of environmental problems: consumption habits and lifestyles. From the point of view of food consumption, the industrial way of life has significantly changed the way we feed. On one hand, the need to work in factories in the late nineteenth and early twentieth century led individuals to eat more meals outside their homes, leaving aside homemade meals prepared directly with in natura foods. The time to sit around the table with the family to have dinner was replaced by fast foods with highly processed ingredients (MINTZ, 2001). On the other hand, the domain of industrial technologies and processes allowed the emergence and proliferation of the food industry that promised a revolution in the act of feeding offering better techniques of food conservation (AZEVEDO, 2012).

The effects of industrialization on food were not limited to the production of canned products at the expense of natural foods. Its main impacts were notably in the agricultural productive sector, which, supported by the development of genetic engineering of food, pesticides, agrochemicals and other chemical additives, promoted a considerable increase in food production globally. The so-called Green Revolution (PINGALI, 2012) promised to end hunger and poverty in the world in a few decades, yet its development in the context of industrial capitalism turned in natura food into commodities, and its potential benefits were reverted exclusively to industry (PETRINI, 2009).

The industrialization of the agricultural sector has caused a global increase in food production and, at the same time, has been changing the relationship between man and his food, which gradually loses contact with the food production cycle, which has influenced the local cuisine identity, the time to prepare, the taste and the balance of a healthy food diet (PETRINI, 2009; CONTREAS, 2005; MINTZ, 2001).

Portilho (2005: 15) points out that these are questions related not only to the production of intra-generational but to intergenerational inequalities. The new critical issue is: will certain consumption patterns turn impossible to guarantee equivalent environmental services for future generations?

The critical awareness of Brazilian society about the practices of consumption of products and services, as well as sustainable food, can be brought to the sphere of childhood and adolescence to what affects the impact of consumerism in the formation of new values of society (INSTITUTO ALANA, 2012). The values involved in the childhood and youth are exactly those that will validate the quality of foods available to the table. Thus, it becomes important to check how the new generation of consumers are considering sustainable food.

In Brazil, there is no research that explores the perspective of students, urban youth, and particularly those who grow up disconnected from the process of growing food, consuming cheap, large-scale products produced in unhealthy environments and unsustainable processes.

\subsection{Design for social action}

Victor Papanek in the book Design for the Real World, which was first published in the beginning of the 1970s is well-recognized for his contribution to include social needs in the design agenda, which means designing for people's needs rather than their wants (PAPANEK, 1985). Examples range from the design of devices for the disabled and children with cerebral palsy to design for the "third world". Margolin and Margolin (2002) recognize the value of Papanek's proposal for social action, and consider that "skills in relating to vulnerable or marginalized populations, rather than to a brief from a manufacturer, need to be developed by future social designers" (MARGOLIN AND MARGOLIN, 2002:29).

In the field of service design, services should be designed based on a genuine comprehension of the purpose, the demand and the ability of the service provider to deliver that service. They can then be iterated and improved to add value based on user/customer feedback and should be designed and delivered in collaboration with all relevant stakeholders (both external and internal) in that concern (IDF, 2017).

Participatory models for managing and conducting development projects have been singled out as successful as they highlight the "voice of the people". In this sense, White (2003) highlights the role of communication as a fundamental tool in this type of process.

Participatory workshop was organised to bring a group of people together and seek their opinions, extract their knowledge and to solve problems in a collaborative and creative environment. The technics includes group dynamics, as well as audio and vídeo practices. Participatory video has been used internationally for various applications such as project monitoring and evaluation, natural resource management, education, communication and advocacy, and emancipation of disadvantaged social groups (WHITE, 2003).

\subsection{University social extension}

The university plays a very important social role in the socialization of scientific knowledge, especially in order to improve the quality of life offering educational services, scientific research and social extension projects.

The Federal University of Rio de Janeiro - UFRJ adopts the concept of university extension, defined by the Public Institutions of Higher Education in Brazilian Forum for Pro-Rectors of Extension (FORPROEX, $\underline{2010)}$ :

"The University Extension, under the constitutional principle of the indissociability between teaching, research and extension, is an interdisciplinary educational, cultural, scientific and political process that promotes 
the transformative interaction between university and other sectors of society".

From this understanding, the guidelines for UFRJ extension programme are: (1) dialogic interaction; (2) interdisciplinarity and interprofessionality; indissociability of teaching - research - extension; (4) impact on student training; and (5) impact on social transformation.

Especially, the "dialogic interaction" guideline points to the development of relations between the University and social sectors marked by dialogue and exchange of knowledge, thus overcoming the discourse of academic hegemony and replacing it with the idea of an alliance with social movements, sectors and organizations. It is no longer a matter of "extending to society the knowledge accumulated by the University", but producing, in interaction with society, new knowledge. "A knowledge that contributes to overcoming inequality and social exclusion and to building a more fair, ethical and democratic society" (UFRJ, 2017). On practice, according to UFRJ's guidelines, for the dialogic interaction it is necessary to apply methodologies that stimulate the participation and democratization of knowledge, highlighting the contribution of nonuniversity actors in their production and diffusion.

\section{Case "food 2.0: sustainable food futures - young people's views from Rio and London" project in Rio de Janeiro.}

Government policies, including the school meals policy, focus on reducing inequality and have shown some effect. Less heard is the perspective of youths from disadvantaged urban areas, such as favelas, on their own hoped-for food futures.

A group of lecturers with an academic background associated to LTDS - COPPE (Alberto Luiz Coimbra Institute of Pos-graduate and Research Engineering) / UFRJ has been conducting research projects in the area of ethical consumption. In 2015, the project "Choices ESRC-DFID - Leveraging Buying Power for Development: Ethical Consumption and Sustainable Procurement in Chile and Brazil" conducted representative surveys and found overwhelming evidence that Brazilians support sustainable public procurement and the new school meals policy which promotes organic and regional food from family farms.

There is a gap in the literature in this field of research, since $90 \%$ of ethical consumer studies have analysed American or European consumers (COTTE \& TRUDEL, 2009). In Southern countries the growing focus has been given to the debate on food sovereignty, a movement that affirms the people's right to define their own food systems (VIA CAMPESINA, 1996). In the $\mathrm{UK}$, in changing urban environments, inequalities in food security are addressed ranging from access to healthier and more sustainable options to the health impact of the population.
Ethical consumption is a research area in which global North and middle-class research subjects dominate (COTTE \& TRUDEL, 2009). Further, this research area has not sufficiently engaged with the growing urban food sovereignty debates. Brazil has recently introduced a pioneering school meals policy which stresses children's right to healthy and culturally appropriate food, buys $30 \%$ of ingredients from local family farms and pays a premium for organic produce (BARTHOLO, AFONSO, PEREIRA, 2012). To our knowledge no research has yet been conducted exploring the young' perspective. Urban youths in particular grows up disconnected from the farming process and tempted by cheap, unhealthy and unsustainably produced food.

\subsection{Action research project concept and objectives}

Choices - ESRC-DFID was a reference in designing the FOOD 2.0, a project of action research. In partnership with Royal Holloway University ${ }^{2}$, LTDS's lecturers aims at raising issues on the youth perspective on fair and sustainable food.

Food 2.0 project was designed to build on 1) exploring how urban youths themselves envision fair and sustainable food; 2) breaking open the frequently criticised global North and global South dichotomy using the audio-visual experience of urban youth in Rio and London in dialogue with each other; 3) continuing to promote the impact agenda on sustainable food procurement.

As an interdisciplinary project, it explored with youth in low income urban settings how they conceptualise sustainable food. Focusing on 18-29-year-old youths, this research partnership sought to answer the following research questions:

- How do urban youths envision fair and sustainable food futures?

- Based in an urban context, how do they conceptualise notions of food sovereignty and food justice?

- How useful is participatory video as a methodology to explore this?

- Which further participatory tools can help youths' voices be heard by policy makers, the media and general public?

The participants were invited to collaborate during 4 workshops on themes related to food and sustainability, and after all they should create a short video (maximum 5 minutes) about food future. The best video, chose by

\footnotetext{
${ }^{2}$ In Rio, the NGO partner was Observatório de Favelas which employs video to document the lives and views of youth from Rio's favelas with one of the aims being impacting urban policy. In London, the Ovalhouse Theatre in Lambeth uses youth-directed theatre and video to communicate the perspectives of disadvantaged youth.
} 
researchers and audio-visual specialists earned a travel to London. The same process occurred before in London, and a group of 4 youth come to Rio on February, 2016.

\subsection{Procedure}

Four workshops were held in Observatory of Favelas (Maré, Rio de Janeiro) with young people from the favelas of Rio de Janeiro ${ }^{3}$, university lecturers and students from UFRJ and UNIRIO (Faculties of Business and Gastronomy of UFRJ and Industrial Engineering of UNIRIO, both Federal Universities). The activities aimed to stimulate critical observation on daily food consumption practices, serving as a window for a deeper analysis of the social construction of food production and consumption images. It was used from informative videos and practical learning to taste and smell experiences.

The dialogue between the thematic content and the audio-visual technique took place from the elaboration of the script, capture of the images and edition of short movies, accompanied by the facilitators of the workshops, and stimulating the personal identity (authorship) of the participant in the final product. After the workshops, a final reunion with lecturers, students, participants and NGO's representants and public managers discussed the results of the workshops and presented the winner for best short movie.

The workshops theme and discussions are described below.

Workshop 1 - Theme: "Food culture in the periphery". Participants were encouraged to reflect on the topic through three questions that guided the debate in groups: What is eating for you? What do you eat daily and where does food come from? What is your involvement in preparing food at home?

The results were shown on posters, where the participants presented their experiences and perceptions about their "food culture". In the Coffee Break, inaugurating a series of gastronomic experiences brought in the Workshops, the students of Gastronomy undergraduate course (UFRJ) brought the "affective foods": past recipes from generation to generation in their families. At home, participants were invited to record interviews with their family and friends about the culture and eating habits. The result was posted on the FOOD 2.0 Facebook page.

Workshop 2 - Theme: "Food waste: ugly food and full use of food". Debate on some of the cases exposed in short interviewed filmed by participants at home. Videos were presented to bring elements on the theme for the debate: "Ilha das flores" (FURTADO, J., 1989) and "Inglorious food" (Intermarche). Participants

\footnotetext{
${ }^{3} 18$ teams were enrolled and 10 were pre-selected for interviews, referring to those who fulfilled the requirements of the Call for Participants.
}

prepared snacks, receiving tips and recipes produced with peels, seeds and stalks of vegetables and fruits.

Workshop 3 - Theme: "Urban agriculture and community gardens". The guiding questions of the debate was: What is urban agriculture? What are the benefits / importance of urban agriculture? How could it be possible to grow food in the place where I live? Participants watched the short movie "Bucket Revolution" (from the original 'Revolução dos Baldinhos'), a social technology created to combat the pest of rats. In the dynamic "Sensory analysis of aromatic herbs and the dangers of ready-made spices", participants were invited to identify different herbs used in Brazilian cooking through smell. After the snack break were presented solutions of urban gardens with low financial cost and use of the spaces at home and the participants built their own gardens using recyclable material (PET bottles and long life cartoons).

Workshop 4 - Theme: "New forms of food production and consumption in cities' periphery". The subjects discussed were: conscious consumption, seasonality of food, local foods, short marketing circuits, price transparency, relational question, direct contact between producer and consumer. Screenplay of the short movie "Armazém Paraopeba", a traditional warehouse that works as a network in a small homonymous community. Discussion of organic food production and consumption systems cases occurring nowadays in the city of Rio de Janeiro. And in the sequence, the participants met in their groups, according to inscription and began planning for the creation of their own short movies.

Final workshop - presentation of the project's concept, aims and main results; dynamics called "aquarius" seeking to provide issues to the question of the project: What is the desirable future of food? In the dynamic were arranged 4 seats in front of the great circle formed by the present public. Only three of them could be occupied, always leaving one available for entry and exit from the debate. In order to participate it was necessary to come to the chairs.

On the afternoon of the awards, the videos of all the participants were shown, and finally the winners were nominated: "The Slum Food Trio" group with the video "Raiz" - Root. The short movie tells the story of the family production chain of the tapioca, a typical Brazilian food, been sold for years by Dani França in Favela da Maré ${ }^{4}$.

In London, the group visited the London University, NGOs partners, organic farms and projects related to agriculture with a lower environmental impact, besides

\footnotetext{
${ }^{4}$ Competing groups and videos: Group Trio Bioporã - Video: You Food: https://youtu.be/Uv1aGKGT8iU; Corte Seco Group - Video: More Maré: https://www.youtube.com/watch?v=wBIY3UPeByc; TEA Group - Taste and Experience of Angatu - Video: Sabor e experiência do bem estar: https://youtu.be/6XmqbeMjuWE; Meninas Quebradeiras Group - Video: A arte de comer: https://www.youtube.com/watch?v=GPvUmH3mZCA
} 
carrying out tourism activities. In Royal Holloway University another workshop was conducted by the English researcher, using participative methodology to identify similarities and differences between the food issues in Brazil and in London.

\subsection{Main results}

Virtual communication facilities were created for the project, involving a team, a group of UFRJ students, workshop participants and the public. COPPE's communications advisor supported the project using its social networks and mailing lists to disseminate the project objectives and main expected results. The journalists interviewed the participants and took photos during the workshops.

During the workshops, some results could be observed on discussions about affective food and the changing of habits generation to generation; the domestic reality and community reality; the natural foods and the industrialized ones; Green revolution and the promise to eradicate hunger; Food waste in the production chain; The importance of aesthetics in marketing; And the influence of the media in purchasing decisions.

At final, 4 short videos and one winner: ROOT. One of the judies said: "It's exciting to see the man's relationship with the land, the possibility of rebuilding, the rebirth of a place that was devastated. The team follows this story with respect to the interviewee's time, which makes the video more sensitive. The issue of food goes in organically, without theories. That's it".

During the debate promoted by the English partners in London, the participants pointed issues around: value of organic, value of food for childhood (obesity), value of family farming, fair trade and food justice, the problem of overfishing (predatory fishing), issues on Brexit / production rules, agriculture scale, the relative weight of food compared to the cost of living, family production $\mathrm{x}$ local production, access to food, Information / income, recognition of traditional food and the right to choose.

New ideas emerged and were designed from what was seen in London: producer appreciation without broker (fair trade), diffusion of green labels, organization of production and distribution of family agriculture / family business (taking off the intermediate), promote green belt, and finally, the concept of pubs as community goods.

\section{Conclusions on service design and academic research as university social extension}

The University extension project Food 2.0, inspired by design for social action, explored with urban youth the concept of sustainable food, justice and urban food sovereignty, using design tools in workshops of discussion and sensorial experiences, promoting debates and showing around the videos produced by the participants.

The London-Rio partnership has deepened the experience of sustainable consumption research between RHUL (UK) and UFRJ (Brazil), specifically in the language of digital media aimed at the youth of the periphery in issues that emerge from the challenge of social inequality. During the planning process between the teams it was possible to make comparisons between research practices and to prepare a future joint research agenda. From a research point of view, as a methodology and involvement with the participants, the researchers, many of them young undergraduates, were trained in participatory methodologies.

With the results, it was possible to verify in the short movies produced by the youths, the reflection on the subject of food sovereignty and the future of food. In terms of content, the groups produced a rather critical discourse: against explorations of the "economic, industrial and media (big media) system," with emphasis on cases that counter the criticized model: traditional, local, community initiatives. With creativity, these short movies have reflected the resilience of young people in the peripheries, bringing their voice to the public in the political arena and in instances of cooperation for development.

Regarding the research questions, some answers were collected during the Workshop. Urban youths imagine the future of food in a fair and sustainable way based on:

- Access to information on food consumed;

- Active political engagement in food production;

- Food education promoting healthier choices;

- Access to the means of production and consumption of food;

- Active political engagement in consumption methods; and

- Recovering and updating traditional values on food.

\section{References}

AZEVEDO, E; PELICIONI, M.C.F.. Promoção da Saúde, Sustentabilidade e Agroecologia: uma discussão intersetorial. Rev. Saúde Soc., v.20, n.3, p.715-729, São Paulo, SP, Brasil, 2011.

BARLETT, P. F.. Campus Sustainable Food Projects: Critique and Engagement. American Anthropologist, 113: $101-115, \quad 2011$. doi:10.1111/j.15481433.2010.01309.x

BARTHOLO, R.; AFONSO, R.; PEREIRA, I..Report: Leveraging Buying Power for Development: Ethical Consumption and Sustainable Procurement in Chile and Brazil. Rio de Janeiro:LTDS/COPPE/UFRJ, 2012. 
CONTREAS, J.. In CANESQUI, A.M.; GARCIA, R. W.D. (orgs). Antropologia e Nutrição um diálogo possivel. Rio de Janeiro: Editora FIOCRUZ, 2005.

COTTE, J; TRUDEL, R.. Socially conscious consumerism: A systematic review of the body of knowledge. MIT Sloan Management Review; Cambridge 50.2 : 61-68, Winter, 2009.

INSTITUTO ALANA. $O$ Instituto. Available at http://www.alana.org.br/Institucional/Instituto.aspx Acessed Jan/2017.

MARGOLIN, V., \& MARGOLIN, S. A "social model" of design: Issues of practice and research. Design Issues, 18(4), 24-30, 2002.

MINTZ, S. Comida e antropologia: uma breve revisão. Rev Bras. de Ciências Sociais, vol. 16, nº 47, out., 2001.

PAPANEK, V.. Design for the real world: Human ecology and social change. Chicago, IL: Academy Chicago Publishers, 1985.

PETRINI, C. Slow Food: princípios da nova gastronomia. São Paulo: SENAC, 2009.

PINGALI, P. L.. Green revolution: impacts, limits, and the path ahead. Proceedings of the National Academy of Sciences of the United States of America, 31 July 2012, Vol.109(31), pp.12302-8, 2012.

PORTILHO, F.. Consumo, sustentabilidade e cidadania. 2a edição. São Paulo: Cortez Editora, 2005.

VIA CAMPESINA. The right to produce and access to land. Position of the Via Campesina on Food Sovereignty presented at the World Food Summit, Rome, Italy, p. 13-17, 1996.

WHITE, S. (Ed.). Participatory video: Images that transform and empower. London: Sage. 2003. 